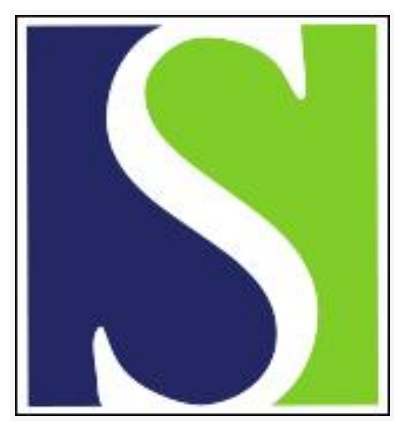

Scand J Work Environ Health 2003;29(1):35-39

https://doi.org/10.5271/sjweh.702

Issue date: Feb 2003

Risk factors predicting hip pain in a 5-year prospective cohort study

by Tüchsen F, Hannerz H, Burr H, Lund T, Krause N

Affiliation: Department of Occupational Health Surveillance and Epidemiology, National Institute of Occupational Health, Lersø Parkallé 105, DK-2100 Copenhagen Ø, Denmark. ft@ami.dk

The following articles refer to this text: 2003;29(4):270-279; SJWEH

Supplements 2008;(5):22-26

Key terms: farming; hip pain; obesity; occupation; prospective cohort study; risk factor

This article in PubMed: www.ncbi.nlm.nih.gov/pubmed/12630434

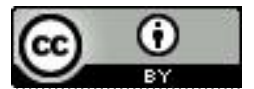




\title{
Risk factors predicting hip pain in a 5-year prospective cohort study
}

\author{
by Finn Tüchsen, MSc, ${ }^{1}$ Harald Hannerz, PhLic, ${ }^{1}$ Hermann Burr, PhD, ${ }^{1}$ Thomas Lund, PhD, ${ }^{1}$ Niklas \\ Krause, $M D^{2}$
}

\begin{abstract}
Tüchsen F, Hannerz H, Burr H, Lund T, Krause N. Risk factors predicting hip pain in a 5-year prospective cohort study. Scand J Work Environ Health 2003;29(1):35-39.

Objectives The aim of the study was to identify and quantify risk factors for hip pain.

Methods A representative sample of 5001 Danish men and women aged 18-65 years in 1990 were interviewed about occupational exposures (response rate 90\%); 5 years later they were reinterviewed about hip pain (response rate $86 \%$ ). Logistic regression with forced entry of all the independent variables was used to estimate the odds ratios for the possible risk factors. The impact of the various predictors was assessed through the calculation of population etiologic fractions.

Results A double risk of hip pain was found for the women as compared with the men [odds ratio (OR) 2.28, 95\% confidence interval (95\% CI) 1.68-3.09]. The risk increased with body mass index. Whole-body vibration (OR 1.86, 95\% CI 1.09-2.71) and physically demanding work (OR 1.83, 95\% CI 1.23-2.71) were strong predictors of hip pain, while a squatting work posture was protective (OR 0.64, 95\% CI 0.42-0.98). The impact of the statistically significant predictors (the etiologic fractions) was as follows: 0.49 for body mass index, 0.05 for whole body vibration, 0.10 for physically demanding work, and 0.32 for squatting (preventive).

Conclusions Female gender, age, high body mass index, whole-body vibration, and physically demanding work are significant risk factors for hip pain.
\end{abstract}

Key terms farming, obesity, occupation

Pain in the hip may impair quality of life and even prevent people from doing jobs they would rather have performed had it not been for the pain. Pain in the hip is also an antecedent and a symptom of radiologically and clinically verified coxarthrosis. Birrell et al (1) found that, among patients examined for the first time for hip pain, as many as $44 \%$ had radiographic changes in the painful hip. Minimum joint space of $2.5 \mathrm{~mm}$ was found in $30 \%$. The overall impact on health was substantial even before the first consultation. Three-quarters of the patients needed analgesics, half used topical creams or ointments, and one in eight used a walking stick (2). We therefore considered hip pain to be an important outcome in itself and also useful as a proxy measure of coxarthrosis.
It is well documented that farmers have a high risk of coxarthrosis, and a new Danish study has shown that employed farm workers also have a high and increasing risk of hospitalization due to coxarthrosis (3). We found only one study relating occupation to hip pain. The lifetime incidence of hip pain was higher among farmers (4). It is still not clear, however, what causes the differential admission rates between occupations. One of the major problems in the study of coxarthrosis is selection out of the occupation (the healthy worker effect). Gradually increasing pain may force workers to change jobs years before the clinical diagnosis, especially if they must continually stand while working or must do hard physical labor. Another problem is recall bias in the exposure assessment of retrospective

1 Department of Occupational Health Surveillance and Epidemiology, National Institute of Occupational Health, Copenhagen, Denmark.

2 Department of Medicine, Division of Occupational and Environmental Medicine, University of California at San Francisco, San Francisco, California, United States.

Reprint requests to: Mr Finn Tüchsen, Department of Occupational Health Surveillance and Epidemiology, National Institute of Occupational Health, Lers $\varnothing$ Parkallé 105, DK-2100 Copenhagen Ø, Denmark. [E-mail: ft@ami.dk] 
studies. Ideally, a prospective study of the incidence of clinically manifest coxarthrosis could overcome these limitations. However, the diagnostic measures needed for a large population is costly and ethically problematic for use with asymptomatic people. Furthermore, the relative low incidence rates in younger populations render such an approach unfeasible. Only two retrospective studies have been done on coxarthrosis, and they are both based on record linkage of hospitalizations (5, 3 ). Most researchers used a cross-sectional (6-9) or case-referent (10-24) design to study occupational risk factors of coxarthrosis. Unfortunately, case-referent studies still remain vulnerable to recall bias in retrospective exposure assessment.

To overcome this difficulty, we designed a prospective study with self-reported hip pain as a proxy outcome measure for coxarthrosis. Hip pain is both a precursor and a symptom of manifest coxarthrosis. Of course, hip pain is not identical with coxarthrosis and may, in some cases, represent referred pain from musculoskeletal disorders of the knee or back. However, it has been shown that a substantial proportion of the hip pain sufferers seeking primary care show radiological signs of coxarthrosis [eg, $44 \%$ in the study of Birrell et al (1)]. In addition, hip pain is the main coxarthrosis symptom leading to health care utilization and disability. In fact, hip pain and associated reductions in the range of motion may be disabling without or before any radiological verification of coxarthrosis.

The aim of our study was to identify risk factors for hip pain and to estimate the odds ratios and etiologic fractions. Etiologic fractions are useful for setting priorities for preventive measures because they indicate the proportion of cases in a population that can be prevented by the respective causal agent.

\section{Subjects and methods}

We drew a random sample of 9653 people, aged 18 to 59 years, from the Central Population Register in 1990. A total of 8664 people, or $90 \%$, agreed to be interviewed. Of the respondents, 5940 were employed at the time of the interview or had been employed up to 2 months before. In 1995 the employees from 1990 were interviewed again. Of the initial 5940 people, 5820 were still alive and a resident of Denmark. A total of 5001 people (86\%) agreed to be interviewed again. More details about the study can be found in the report by Feveile et al (25).

However, of the employees in 1990, only the 3990 respondents who were still employees in 1995 were interviewed regarding the prevalence of hip pain. The group of respondents not interviewed in 1995 regard- ing hip pain consisted of self-employed people (N 153), those on leave (N 152), those unemployed $>2$ months (N 252), disability pensioners or those listed as sick for $>2$ months (N 199), early retirement pensioners (N 158), students or draftees (N 79), and "others" (N 18). We calculated therefore the possible excess risk of not being interviewed regarding hip pain in 1995 given prevalent hip pain in 1990 as compared with those without hip pain in 1990. After adjustment for gender and age, we found a $20 \%$ nonsignificant excess risk of not being interviewed regarding hip pain in 1995 among those with hip pain in 1990. The consequences for our results are likely to be conservative estimates.

A total of 3714 people who, in 1990, did not state that they "at any point in time within the last 12 months had trouble (pain or malaise) in one or both hips" were included in the follow-up analysis.

We used a logistic regression analysis to estimate the odds ratios. The analysis included the following variables: gender, age, weight and height, whole-body vibration, physically demanding work ("Is your work so physically hard that you breathe faster?"), heavy lifting $(>20 \mathrm{~kg}$ ), sitting work, squatting work, and daily smoking. The model passed a Hosmer-Lemeshow test (26) for goodness-of-fit ( $\mathrm{P}=0.53)$.

Etiologic fractions were calculated using the estimates of odds ratios as the relative risk and the fraction of exposed in this representative cohort as the estimate of the exposed fraction in the Danish working population.

\section{Results}

A total of 223 incident cases of hip pain were observed during the 5-year follow-up period, 132 among the men and 91 among the women.

Table 1 shows the odds ratios (OR) for the demographic, anthropometric, behavioral, and occupational risk factors after adjustment for each other. The women experienced hip pain twice as often as the men.

A higher risk of hip pain was observed for persons older than 30 years. This association was not statistically significant. Body mass index showed a positive dose-response relationship with hip pain. Smoking did not predict hip pain. No interactions between these factors and age or gender were observed.

The following two occupational factors were significant predictors of hip pain: physically demanding work (OR 1.89, $95 \%$ CI 1.09-3.18) and whole-body vibration (OR 1.83, 95\% CI 1.23-2.71). Both nearly doubled the risk of hip pain. Squatting for at least one-fourth of the workhours reduced the risk of hip pain by a factor of 1.56 (OR $0.64,95 \%$ CI $0.42-0.98$ ). One could also 
Table 1. Number of exposed people, the odds ratios for the 5 -year incidence of hip pain with the $95 \%$ confidence intervals, and the etiologic fractions.

\begin{tabular}{|c|c|c|c|c|}
\hline Predictor & N & Odds ratio & $95 \%$ confidence interval & Etiologic fractions \\
\hline Gender $(P=0.0000)$ & & & & 0.37 \\
\hline $\begin{array}{l}\text { Men } \\
\text { Women }\end{array}$ & $\begin{array}{l}2030 \\
1684\end{array}$ & $\begin{array}{l}1.00 \\
2.28\end{array}$ & 1.68-3.09 & \\
\hline Age $(P=0.1447)$ & & & & 0.24 \\
\hline $18-30$ years & 1146 & 1.00 & . & \\
\hline $30-39$ years & 1157 & 1.49 & $1.03-2.16$ & \\
\hline 40-49 years & 1017 & 1.39 & $0.94-2.05$ & \\
\hline $50-59$ years & 394 & 1.54 & $0.94-2.52$ & \\
\hline Body mass index (0.0054) & & & & 0.49 \\
\hline$<20 \mathrm{~kg} / \mathrm{m}^{2}$ & 473 & 1.00 & . & \\
\hline $20-24 \mathrm{~kg} / \mathrm{m}^{2}$ & 2271 & 1.99 & $1.21-3.30$ & \\
\hline $25-29 \mathrm{~kg} / \mathrm{m}^{2}$ & 827 & 2.19 & $1.23-3.89$ & \\
\hline$\geq 30 \mathrm{~kg} / \mathrm{m}^{2}$ & 143 & 3.47 & $1.64-7.31$ & \\
\hline Daily smoking $(P=0.4105)$ & & & & 0.05 \\
\hline No & 2065 & 1.00 & . & \\
\hline Yes & 1649 & 1.12 & $0.85-1.48$ & \\
\hline Physically demanding work $(P=0.0033)$ & & & & 0.10 \\
\hline Seldom or never & 3207 & 1.00 & . & \\
\hline$\geq 25 \%$ of workhours & 507 & 1.83 & $1.23-2.71$ & \\
\hline Whole-body vibration $(P=0.0325)$ & & & & 0.05 \\
\hline Seldom or never & 3505 & 1.00 & . & \\
\hline$\geq 25 \%$ of workhours & 209 & 1.86 & $1.09-3.18$ & \\
\hline Work in a squatting position $(\mathrm{P}=0.0319)$ & & & & 0.32 \\
\hline Seldom or never & 3097 & 1.00 & $\cdot$ & \\
\hline$\geq 25 \%$ of workhours & 617 & 0.64 & $0.42-0.98$ & \\
\hline Sitting work $(P=0.4679)$ & & & & 0.08 \\
\hline$\geq 75 \%$ of workhours & 1294 & 1.00 & . & \\
\hline $25 \%$ or $50 \%$ of workhours & 1089 & 1.03 & $0.72-1.48$ & \\
\hline Seldom or never & 1331 & 1.23 & $0.86-1.75$ & \\
\hline Heavy lifting $(P=0.7833)$ & & & & 0.01 \\
\hline Seldom or never & 3136 & 1.00 & . & \\
\hline$\geq 25 \%$ of workhours & 578 & 1.08 & $0.72-1.63$ & \\
\hline
\end{tabular}

imagine that obese people do not do squatting work, but we found no difference in the proportion of squatting according to body mass index (BMI). Sitting less than one-fourth of the workhours, or seldom or never, and heavy lifting did not predict hip pain.

The etiologic fractions for each risk factor are shown in the last column of table 1 . When the statistically significant predictors that are preventable were focused on, the etiologic fraction was $49 \%$ for a high BMI, $10 \%$ for physically demanding work, and $5 \%$ for whole-body vibration. Together these three risk factors accounted for an etiologic fraction of 0.57 .

\section{Discussion}

The women in our study experienced hip pain twice as often as the men. An increasing BMI also predicted hip pain. Whole-body vibration and physically demanding work were strong predictors of hip pain, while a squat- ting work posture was a protective factor. Among the preventable risk factors, BMI, heavy physical labor, and whole-body vibration together accounted for an etiologic fraction of 0.57

A major strength of our study was its prospective design. In fact it was the first prospective study of hip pain. A previous study of hip pain among farmers was cross-sectional (4). Most previous studies of coxarthrosis and work conditions have been either cross-sectional (6-9) or case-referent with retrospective assessment of exposure subject to recall bias (10-24).

Our prospective design allowed us to exclude prevalent cases and to eliminate recall bias. Hip pain may occur much earlier than the diagnosis of coxarthrosis, and it therefore may be more closely related to the risk factors under study. However, some hip pain cases may be intermittent. We found that $42 \%$ of the men and $48 \%$ of the women, over 35 years, who reported hip pain in 1990 still had hip pain 5 years later. Among those under 35 years of age, only half as many still had pain after 5 years. So far we have not been able to demonstrate that self-reported hip pain was the first sign 
of coxarthrosis in our cohort. However, Birrell et al (1) have shown that new cases of hip pain in primary health care units often have advanced radiographic changes that qualify for the diagnosis of coxarthrosis.

Our follow-up time was limited to 5 years. This period may be considered too short for the development of coxarthrosis. However, it may be sufficient for the development of hip pain. In fact, the follow-up period did yield 223 incident cases of hip pain in a working population of 5001 persons and therefore allowed for a multivariate analysis of the predictors.

The direction and strength of the association between BMI and hip pain is comparable to the associations found between BMI and coxarthrosis in previous casereferent studies [eg, those of Croft et al (16) and Vingård et al (13)]. In general, obesity needs to be conceptualized as both a risk factor and a consequence of coxarthrosis, the latter due to movement restrictions. Given the prospective design and our ability to control for other individual and occupational risk factors, the results of our study support a causal interpretation of the association between obesity and hip pain. Additional studies are needed to confirm this association prospectively for coxarthrosis.

Physically demanding work was strongly associated with hip pain (OR 1.83, 95\% CI 1.23-2.71) even after control for confounding factors. Similarly, Typpö (7) found a strong association between coxarthrosis due to hard physical labor (OR 1.97, 95\% CI 1.14-3.41), and Vingård et al (10) found an relative risk of $1.82(95 \% \mathrm{CI}$ 1.02-3.24) for medium exposure to static and dynamic work and 2.42 (95\% CI 1.45-4.04) for high exposure. In a more recent study, the latter authors found that a combination of physical loads both at work and during sports activities could raise the relative risk of total hip replacement to 4.3 (95\% CI 1.7-11.0) (11), and Roach et al (21) found an odds ratio of 2.5 (95\% CI 1.5-5.0) for heavy work after control for cancer, obesity at the age of 40 years, and running.

We found that squatting is a significant protective factor for hip pain. This finding is in accordance with the tendency already found in 1992 by Croft et al (16), who reported that squatting is protective for coxarthrosis. They calculated an odds ratio of 0.7 for coxarthrosis (95\% CI 0.4-1.4) for people squatting more than 30 minutes a day. Beginning coxarthrosis and hip pain are accompanied by a typical pattern of hip joint movement restriction due to contracted hip muscles and connective tissues (27). It can be hypothesized that squatting postures play a role in preventing this development by stretching some of the typically contracted leg and hip muscles. A total of $65 \%$ of those with squatting work in 1990 no longer performed squatting at work in 1995. There was no significant risk difference, however, between those who did squatting both in 1990 and 1995 and those who were only exposed at the beginning of the study or at the time of the follow-up. One could also imagine that obese people do not do squatting work, but we found no difference in the proportion of persons squatting according to the BMI.

We found only a slight and statistically insignificant increase in hip pain in association with heavy lifting, while heavy lifting has been reported as a strong risk factor for coxarthrosis by Jacobsson et al (OR 2.42, 95\% CI 1.33-4.41) (17) and Yoshimura et al (OR 4.1, 95\% CI 1.1-15.2) (14). However, our measurement was rather crude, based exclusively on self-reports, and included only two categories of current lifting requirements on the job. In addition, we did not measure past cumulative exposure. These limitations may have led to a misclassification of exposure and an underestimation of the effect of lifting.

We did observe a slight increased risk of hip pain among persons who seldom or never sit, but the result was not statistically significant. Others have identified standing at work as a risk factor for coxarthrosis (16, 28). Again, future studies with better exposure assessment are needed to resolve these inconsistencies.

The etiologic fraction measures the fraction of diseased cases attributable to an exposure in a population and the fraction that would not have been observed if the exposure had been nonexistent. Etiologic fractions cannot be generalized from one country to another. The relative risk may usually be the same, but the proportion of exposed is not necessarily the same. Neither can we expect that etiologic fractions are the same for hip pain and coxarthrosis. Still, however, it may be interesting to compare former calculations of the etiologic fraction for coxarthrosis on the basis of a Swedish casereferent study (18) with our new results on hip pain. Similar to our results, Olsen et al (18) found a significant impact for overweight on coxarthrosis in Sweden (etiologic fraction of 0.16). Hip pain may have more causes than coxarthrosis, and obesity has become more prevalent. Still, it is a bit surprising that we found an etiologic fraction of 0.49 for a high BMI. In Sweden the etiologic fraction for coxarthrosis due to physical workload was as high as 0.4 (18). We calculated the impact of physically demanding work on hip pain to have an etiologic fraction of 0.10 .

In conclusion, we found an increased risk of hip pain predicted by female gender, previous high body mass index, physically demanding work, and exposure to whole-body vibration. Work in a squatting posture was preventive. Almost half of the hip pain among gainfully employed Danes would not have occurred had no one been overweight or obese. The impact of physically demanding workload and whole-body vibration was also important, and the preventive effect of squatting was substantial. 


\section{References}

1. Birrell F, Croft P, Cooper C, Hosie G, MacFarlane GJ, Silman A. Radiographic change is common in new presenters in primary care with hip pain. PCR Hip Study Group. Rheumatology (Oxford) 2000;39:772-5.

2. Birrell F, Croft P, Cooper C, Hosie G, MacFarlane G, Silman A. Health impact of pain in the hip region with and without radiographic evidence of osteoarthritis: a study of new attenders to primary care: The PCR Hip Study Group. Ann Rheum Dis 2000;59:857-63.

3. Tüchsen F, Hannerz H, Jensen MV, Krause N. Socio-economic status, occupation and risk of hospitalisation due to coxarthrosis in Denmark 1981-1999. Ann Rheum Dis. In press.

4. Stiernstrom EL, Holmberg S, Thelin A, Svardsudd K. Reported health status among farmers and nonfarmers in nine rural districts. J Occup Environ Med 1998;40:917-24.

5. Vingård E, Alfredsson L, Goldie I, Hogstedt C. Occupation and osteoarthrosis of the hip and knee: a register-based cohort study. Int J Epidemiol 1991 20:1025-31.

6. Lindberg H, Danielsson LG. The relation between labor and coxarthrosis. Clin Orthop 1984;191:159-61.

7. Typpö T. Osteoarthritis of the hip. Radiologic findings and etiology. Ann Chir Gynaecol Suppl 1985;201:1-38.

8. Croft P, Coggon D, Cruddas M, Cooper C. Osteoarthritis of the hip: an occupational disease in farmers. BMJ 1992;304: 1269-72.

9. Heliövaara M, Makela M, Impivaara O, Knekt P, Aromaa A, Sievers K. Association of overweight, trauma and workload with coxarthrosis: a health survey of 7,217 persons. Acta Orthop Scand 1993;64:513-8.

10. Vingård E, Hogstedt C, Alfredsson L, Fellenius E, Goldie I, Köster M. Coxarthrosis and physical work load. Scand J Work Environ Health 1991;17:104-9.

11. Vingård E, Alfredsson L, Malchau H. Osteoarthrosis of the hip in women and its relation to physical load at work and in the home. Ann Rheum Dis 1997;56:293-8.

12. Vingård E, Alfredsson L, Malchau H. Osteoarthrosis of the hip in women and its relationship to physical load from sports activities. Am J Sports Med 1998;26:78-82.

13. Vingård E, Alfredsson L, Malchau H. Lifestyle factors and hip arthrosis: a case referent study of body mass index, smoking and hormone therapy in 503 Swedish women. Acta Orthop Scand 1997;68:216-20.

14. Yoshimura N, Sasaki S, Iwasaki K, Danjoh S, Kinoshita H, Yasuda T, et al. Occupational lifting is associated with hip osteoarthritis: a Japanese case-control study. J Rheumatol
2000;27:434-40.

15. Coggon D, Kellingray S, Inskip H, Croft P, Campbell L, Cooper C. Osteoarthritis of the hip and occupational lifting. Am J Epidemiol 1998;147:523-8.

16. Croft P, Cooper C, Wickham C, Coggon D. Osteoarthritis of the hip and occupational activity. Scand J Work Environ Health 1992;18:59-63.

17. Jacobsson B, Dalen N, Tjornstrand B. Coxarthrosis and labour. Int Orthop 1987;11:311-313.

18. Olsen O, Vingård E, Köster M, Alfredsson L. Etiologic fractions for physical work load, sports and overweight in the occurrence of coxarthrosis. Scand J Work Environ Health 1994;20:184-8.

19. Thelin A, Jansson B, Jacobsson B, Strom H. Coxarthrosis and farm work: a case-referent study. Am J Ind Med 1997;32: 497-501.

20. Thelin A. Hip joint arthrosis: an occupational disorder among farmers. Am J Ind Med 1990;18:339-43.

21. Roach KE, Persky V, Miles T, Budiman-Mak E. Biomechanical aspects of occupation and osteoarthritis of the hip: a case-control study. J Rheumatol 1994;21:2334-40.

22. Eastmond CJ, Hudson A, Wright V. A radiological survey of the hips and knees in female specialist teachers of physical education. Scand J Rheumatol 1979; :264-8.

23. White JA, Wright V, Hudson AM. Relationships between habitual physical activity and osteoarthrosis in ageing women. Public Health 1993;107:459-70.

24. Lau EC, Cooper C, Lam D, Chan VN, Tsang KK, Sham A. Factors associated with osteoarthritis of the hip and knee in Hong Kong Chinese: obesity, joint injury, and occupational activities. Am J Epidemiol 2000;152:855-62.

25. Feveile H, Jensen C, Burr H. Risk factors for neck-shoulder and wrist-hand symptoms in a 5-year follow-up study of 3,990 employees in Denmark. Int Arch Occup Environ Health 2002;75:243-51.

26. Hosmer DW, Lemeshow S. Applied logistic regression. New York (NY): John Wiley \& Sons; 1989.

27. Winkel D, Fisher S, Vronge C. Nichtoperative Orthopädie der Weichteile des Bewegungsapparates: Teil 2 Diagnostik [in German]. In: Winkel D, Vleeming A, Fisher S, Meijer OG, Vronge C, editors. Nichtoperative Orthopädie der Weichteile des Bewegungsapparates. Stuttgart (Germany): Gustav Fisher Verlag; 1985.

28. Cvijetic S, Dekanic-Ozegovic D, Campbell L, Cooper C, Potocki K. Occupational physical demands and hip osteoarthritis. Arh Hig Rada Toksikol 1999;50:371-9.

Received for publication: 11 March 2002 